\title{
PLANO DE AÇÕES ARTICULADAS (PAR): DISCURSOS DE PROFESSORES SOBRE A ESCOLA DO CAMPO EM BRAGANÇA-PA
}

\author{
ARTICULATED ACTION PLAN (PAR): TEACHERS 'SPEECHES ON FIELD SCHOOL \\ IN BRAGANÇA-PA
}

\author{
Raquel Amorim dos Santos \\ Profa. Dra. \\ Universidade Federal do Pará - UFPA/ Campus Universitário de Castanhal. \\ Pará Castanhal, Pará - Brasil \\ rakelamorim@ufpa.br \\ Rogerio Andrade Maciel \\ Prof. Dr. \\ Universidade Federal do Pará - UFPA/ Campus Universitário Bragança - Pará \\ Bragança, Pará - Brasil \\ rogeriom@ufpa.br \\ Erica Neiza Ramos Souza \\ Graduada \\ Universidade Federal do Pará - UFPA/ Campus Universitário Bragança - Pará \\ Bragança, Pará - Brasil \\ ericaneiza@yahoo.com.br
}

Resumo: O presente artigo analisa os discursos de quatro professores em duas Escolas do Campo, considerando o Plano de Ações Articuladas (PAR) em Bragança-PA. A metodologia de pesquisa é qualitativa. A coleta de dados foi feita por meio de questionário e entrevista semiestruturada, com uma amostragem constituída de quatro professores que atuam em duas Escolas do Campo. Os dados coletados foram organizados, tabulados e interpretados a partir da Análise do Discurso (AD), com a transcrição total ou parcial dos discursos, considerados mais expressivos. É fato que os investimentos do PAR para o Município de Bragança-PA apresentam-se como fator de transformação na infraestrutura de algumas Escolas do Campo, no entanto, essa política precisa se adequar as especificidades das comunidades campesinas e considerar as opiniões dos profissionais que atuam diretamente nesses espaços, visto que, a infraestrutura é um fator importante que contribui para a qualidade do ensino e da aprendizagem dos alunos do campo em BragançaPA.

Palavras-chave: plano de ações articuladas; educação do campo; qualidade do Ensino-aprendizagem.

\begin{abstract}
This paper analyzes the discourses of four teachers in two rural schools, considering the Articulated Action Plan (PAR) in Bragança-PA. The research methodology is qualitative. Data collection was done through a questionnaire and semi-structured interview, with a sample consisting of four teachers who work in two rural schools. The collected data were organized, tabulated and interpreted from the Discourse Analysis (AD), with the total or partial transcription of the discourses, considered more expressive. It is a fact that PAR investments for the Municipality of Bragança-PA present as a factor of transformation in the infrastructure of some schools of the field, however, this policy needs to adapt the specificities of the peasant communities and consider the opinions of the professionals who work. directly in these spaces, since infrastructure is an important factor that contributes to the quality of teaching and learning of students in the field in Bragança-PA.
\end{abstract}

Keywords: articulated action plan; field education; quality of teaching and learning.

Para citar - (ABNT NBR 6023:2018)

SANTOS, Raquel Amorim dos; MACIEL, Rogerio Andrade; SOUZA, Erica Neiza Ramos. Plano de Ações Articuladas (PAR): discursos de professores sobre a escola do campo em Bragança-PA. Eccos - Revista Científica, São Paulo, n. 58, p. 1-20, e15976, jul./set. 2021. Disponível em: https://doi.org/10.5585/eccos.n58.15976. 


\section{Introdução}

Antes de analisar os discursos de professores sobre a escola do campo, considerando o Plano de Ações Articuladas (PAR), é preciso mencionar que este é composto por um conjunto de estratégias associadas ao Plano de Desenvolvimento da Educação (PDE), tendo em vista a materialização do regime de colaboração entre Municípios e entes federados (União, Estados, Distrito Federal e Municípios). A melhoria da qualidade da educação está assentada na possibilidade de articular ações, políticas e programas, criando, assim, uma integração entre os diversos níveis e modalidades da educação nacional (BRASIL, 2017).

Nos últimos quatro anos, o Município de Bragança/PA recebeu, por meio do PAR juntamente com o Fundo Nacional de Desenvolvimento da Educação (FNDE), o financiamento para a construção de vinte quatro novas escolas a serem construídas em diferentes comunidades do campo. Esse financiamento foi firmado por meio do Termo de Compromisso no 22294/2014 em parceria com a Secretaria Municipal de Educação (SEMED). Desse quantitativo de construções, apenas oito escolas foram inauguradas até o início do ano de 2018, dentre elas, destacamos a Escola Municipal de Ensino Fundamental Zacharias Miranda, na Comunidade do Km 10 da PA 112, que liga Bragança ao Montenegro, região rural do município e Escola Municipal de Ensino Fundamental Manoel Lucas, na comunidade de Vila dos Lucas, escolas que se tornaram o lócus desta pesquisa.

O PAR, em sua dimensão de infraestrutura e recursos pedagógicos, propicia aos entes federados municipais a relação de colaboração com a União para que sejam substanciadas as implementações das ações circunscritas nos documentos e materializados.

Nesse âmbito, ressaltamos que esta pesquisa contribui para a ampliação dos conhecimentos sobre o PAR e sua atuação nos diversos Estados e Municípios como o de Bragança-PA, visto que o número de escolas a serem financiadas por essa política pública repercute em crescimento para as comunidades contempladas, expansão e melhoria arquitetônica da escola da Rede de Ensino Municipal. Além disso, a presente investigação oferece subsídios à área científica, uma vez que os dados obtidos são construtivos para novos estudos sobre o PAR e a implementação de políticas de melhoria da qualidade da educação, especialmente a melhoria das condições de infraestrutura na realidade das escolas do campo, considerando que a estrutura dos espaços é importante para o desenvolvimento da aprendizagem.

A Constituição Federal de 1988 garante a todos o direito à educação como dever do Estado e da Família. Nesse sentido, o Estado deve oferecer condições para permanência dos 
alunos na escola, bem como investimentos educacionais para gestão democrática, formação de professores, servidores de apoio, infraestrutura e recursos pedagógicos, entre outros elementos essenciais para o desenvolvimento da qualidade na educação, inclusive para a Educação do Campo.

Sátyro, Ferreira e Soares $(2007$, p.8) afirmam que "[...] a infraestrutura escolar pode exercer influência significativa sobre a qualidade da educação", visto que os espaços escolares são importantes para um melhor aproveitamento da aprendizagem dos alunos, salas arejadas, ventilação e iluminação do ambiente, entre outros, aspectos indispensáveis para o conforto de qualquer pessoa.

\section{Percurso metodológico}

A pesquisa é de abordagem qualitativa por estudar o fenômeno social. Para Minayo (2006), a “pesquisa qualitativa se aprofunda no mundo dos significados. Esse nível de realidade não é visível, precisa ser exposta e interpretada, em primeira instância, pelos próprios pesquisados".

O instrumento para a coleta de dados foi o questionário e a entrevista semiestruturada. Segundo Marconi e Lakatos (2002, p. 98), o “questionário é um instrumento de coleta de dados constituído por uma série ordenada de perguntas, que deve ser respondida por escrito e sem a presença do entrevistador".

Já a entrevista semiestruturada é definida por Marconi e Lakatos (2002, p.94) como "encontro entre duas pessoas, a fim de que uma delas obtenha informações a respeito de um determinado assunto". Ela combina perguntas abertas e fechadas, onde o informante tem a possibilidade de discorrer sobre o tema proposto. Utilizamos a entrevista semiestruturada com aqueles professores que apresentaram dificuldades em responder por escrito o questionário.

O questionário e a entrevista semiestruturada foram constituídos de quinze questões, previamente elaboradas que ajudaram a traçar o perfil identitário e profissional dos professores das respectivas escolas, assim como captar seus discursos a respeito das escolas do campo e seus reflexos no processo de ensino e de aprendizagem a partir do PAR.

O presente estudo realizou a amostragem em duas Escolas Municipais de Bragança Pará: uma situada na comunidade do Km 10 do Montenegro, n. 1 - Escola Municipal de Ensino Fundamental Zacharias da Silveira Miranda; e a outra escola, localizada na Vila dos Lucas, n. 2 - Escola Municipal de Ensino Fundamental Manoel Lucas, ambas do meio rural do município. 
Essas escolas, lócus desta pesquisa foram escolhidas por serem as primeiras inauguradas do montante das vinte e quatro aprovações de financiamento via FNDE.

Os sujeitos da pesquisa foram quatro professores que atuam nos anos iniciais do Ensino Fundamental, sendo um da Escola Manoel Lucas e três da Escola Zacharias. Os critérios para a escolha dos sujeitos foram: a) Professores que atuam em escolas que foram reestruturadas pelo PAR a partir do convênio com SEMED de Bragança-PA; b) Professores que atuam no Ensino Fundamental na Rede Municipal de Ensino nas escolas do campo.

Para preservar a identidade de professores, optamos por identificá-los por letra do alfabeto: Professor A (sexo feminino com dez anos de trabalho); Professor B (sexo feminino com cinco anos de trabalho); Professor C (sexo feminino com menos de cinco anos de trabalho); e o Professor D (sexo masculino com menos de cinco anos de trabalho).

Em relação à faixa etária, os professores entrevistados têm idades variadas entre 26 a 45 anos. No perfil, constatamos que os docentes mais novos têm Licenciatura Plena em Pedagogia, e os mais velhos atuam na Educação Básica com o Magistério, mas continuam atualizando o seu desenvolvimento acadêmico por meio de programas de formação continuada.

A análise dos dados ocorreu a partir da organização e tabulação dos dados de acordo com a ordem das perguntas, com a separação dos discursos a partir da aproximação das respostas. Para o tratamento dos dados, utilizamos a Análise do Discurso, descrita por Orlandi (2001), para quem o discurso remete a ideia de curso, de percurso etc. O discurso é assim a palavra em movimento, onde se observa que o homem falando, não é algo pronto e acabado, fixado em apenas uma interpretação; pelo contrário, o discurso pode ter várias interpretações, depende do pesquisador e de seu posicionamento com relação aos sentidos.

Desse modo, a análise do discurso visa compreender como os objetos simbólicos produzem sentido, analisando, assim, os próprios gestos de interpretação que ela considera como atos no domínio simbólico, pois eles intervêm no real sentido do discurso. É importante destacar que a "análise de discurso não procura o sentido "verdadeiro", mas o real do sentido em sua materialidade linguística e histórica".

\section{Resultados e discussão}

No fim do século XIX e início do século XX, o Estado brasileiro passou a intervir com os modelos educacionais que estavam em desenvolvimento no país. Com o passar dos anos e a criação de leis, como marco inicial a Constituição Federal de 1988, a Lei de Diretrizes e Bases da Educação (LDB) n. 9.394/96, o Plano Nacional de Educação (PNE) de 2011, entre outros 
que estabelecem diretrizes contemporâneas para melhoria da qualidade da educação em nosso país, com vista a ampliação de políticas educacionais para a Educação do Campo.

A educação abre novas propostas educacionais a partir da CF/88 que estabelece:

Art. 206 - O ensino será ministrado com base nos seguintes princípios: VI- garantia de padrão de qualidade.

Art. 211- A União, os Estados, o Distrito federal e os Municípios organizarão em regime de colaboração seus sistemas de ensino.

$\S 1^{\circ}$ - A União organizará o sistema federal de ensino [...] e exercerá em matéria educacional, função redistributiva e supletiva, de forma a garantir a equalização de oportunidades educacionais e padrão mínimo de qualidade do ensino mediante assistência técnica e financeira aos Estados, ao Distrito Federal e aos Municípios. (BRASIL, 1988, s/p).

Em concordância com a CF/88, a LDB n. 9.394/96 institui:

Art. $3^{\circ}-\mathrm{O}$ ensino será ministrado com base nos seguintes princípios:

IX - garantia de padrão de qualidade.

Art. $4^{\circ}-\mathrm{O}$ dever do Estado com educação escolar será efetivado mediante a garantia de:

IX - padrões mínimos de qualidade de ensino, definidos como a variedade e quantidade mínimas, por aluno, de insumos indispensáveis ao desenvolvimento do processo de ensino aprendizagem. (BRASIL, 1996, s/p).

Pensar em qualidade de educação é remeter-se a programas e projetos que tenham como propostas o crescimento e o desenvolvimento dos sistemas educacionais, no entanto, para alcançar tais objetivos, é necessário se adequar as leis e aderir a programas que financiem tais melhorias. A criação da Lei n. 6.094 de 2007 que instituiu o Plano de Metas, foi uma das primeiras propostas do segundo mandato do governo de Luiz Inácio "Lula" da Silva que mais adiante favorece o surgimento do Plano de Desenvolvimento da Educação (PDE), criado com finalidade de deixar, a disposição dos Estados e Municípios, instrumentos eficazes de avaliação e implementação de políticas para a melhoria da qualidade da educação.

O Plano de Lei do PNE 2011-2020 no Art. $8^{\circ}$ institui o prazo de 1 (ano) a partir da publicação da Lei, para elaboração de planos de educação ou adequação dos planos já aprovados, considerando as necessidades específicas das populações do campo. É possível perceber, na medida que as propostas para melhorar a educação avançam, a necessidade de pensar a educação a partir de todos os segmentos que a compõem, de acordo com as necessidades e especificidades de cada população. Todos os cidadãos, segundo a lei, têm os mesmos direitos, desse modo, devemos pensar em educação para todos, incluindo os alunos do campo.

Segundo Lobo e Barbalho (2017, p. 87), a “[...] instituição do Decreto de n 6.094/2007 que versa sobre o Plano de Metas Compromisso Todos pela Educação, lançado paralelo ao PDE 
é o disposto legal que coloca em vigência o PAR" e trata dos critérios, parâmetros e procedimento para obtenção de assistência técnica e financeira da União.

O objetivo do PAR é promover a qualidade da Educação Básica pública, de acordo com a observação das metas, diretrizes e estratégias do PNE. Isso caracteriza o PAR devido o compartilhamento de competências políticas, técnicas e financeiras para execução de programas e desenvolvimento da Educação Básica, objetivando a articulação das ações dos entes federados (União, Estados, Distrito Federal e municípios) em regime de colaboração que está definido no art. $9^{\circ}$ da Lei 6.094/2007 como “[...] um conjunto de ações articuladas, apoiando técnicas e financeiramente pelo Ministério da Educação que visa o cumprimento das técnica do Compromisso e a observância das suas diretrizes" (BRASIL, 2009, s/p).

O processo de elaboração e acompanhamento das ações do PAR é realizado por um sistema virtual denominado de Sistema Integrado de Monitoramento, Execução e Controle do Ministério da Educação (SIMEC), disponibilizado no site do MEC desde 2009.

Nesse ambiente virtual é feito o cadastro dos dirigentes responsáveis pelo lançamento dos dados e ações, e concluída essa etapa, o sistema disponibiliza a elaboração do plano que se dá em três etapas: diagnóstico da situação educacional, elaboração do plano de trabalho e análise técnica. Concluída a etapa do diagnóstico da situação educacional, o ente federado elabora o seu PAR e o apresenta ao FNDE. Cabe ao Ministério da Educação fazer a avaliação dos dados e decidir apoiar técnica e financeiramente os entes federados de acordo com as necessidades educacionais de suas redes de ensino, abrangendo de forma sistemática as etapas e modalidades da Educação Básica conforme a Tabela 1.

Tabela 1 - Abrangência do PAR

\begin{tabular}{|c|c|c|c|c|}
\hline Nivel & Etapa & Modalidades & Açס̋es Pedagógicas & Açס̄es de Infraestrutura \\
\hline $\begin{array}{l}\text { Educaçăo } \\
\text { Básica }\end{array}$ & $\begin{array}{l}\text { - Educaçåo } \\
\text { infantil } \\
\text { - Ensino } \\
\text { fundamental } \\
\text { - Ensino médio }\end{array}$ & $\begin{array}{l}\text { - Educação especial } \\
\text { - Ensino tecnológico e } \\
\text { profissional } \\
\text { - Educaçåo de jovens e } \\
\text { adultos } \\
\text { - Educação ambiental } \\
\text { - Educação do Campo } \\
\text { - Educação étnico-racial } \\
\text { - Educação indigena } \\
\text { - Educaçåo quilombola }\end{array}$ & $\begin{array}{l}\text { - Acervos bibliográficos } \\
\text { - Formaçao continuada e } \\
\text { - Japacitaçăo } \\
\text { - Material didático } \\
\text { - Material pedagógico } \\
\text { - Material escolar } \\
\text { - Material de consumo } \\
\text { - Cursos EAD } \\
\text { - Materiais esportivos }\end{array}$ & $\begin{array}{l}\text { - Ampliação } \\
\text { - Construçăo } \\
\text { - Reforma } \\
\text { - Equipamentos } \\
\text { - Onibus escolares } \\
\text { - Onibus acessivel } \\
\text { - Bicicleta e capacete } \\
\text { - Equipamentos e kit de } \\
\text { - cozinha } \\
\text { - Brinquedos } \\
\text { - Equadras escolares } \\
\text { - Instimatização } \\
\text { - Mobiliário } \\
\text { - Computadores, projetores } \\
\text { e tablets }\end{array}$ \\
\hline
\end{tabular}

Fonte: Portal do MEC/ Par, 2019. https://www.fnde.gov.br/programas/par 
No município de Bragança-PA, podemos perceber ações em diversos níveis de educação, mas para o foco das análises do presente estudo, vimos as ações no Ensino Fundamental, na Modalidade da Educação do Campo no quesito infraestrutura para construção de novos espaços escolares.

O PAR é um conjunto de ações que dependem diretamente do apoio do MEC, tais ações estão inseridas dentro de quatro dimensões, são elas: Gestão Educacional; Formação de Professores; Práticas Pedagógicas e Avaliação; Infraestrutura e Recursos Pedagógicos. Este estudo realiza uma incursão na dimensão quatro que trata da infraestrutura e dos recursos pedagógicos, tratando com mais detalhe a infraestrutura de escolas do campo do município de Bragança-PA.

A Rede Municipal de Ensino em Bragança-PA, segundo dados do Departamento de Estatística da SEMED, do ano 2017, é composta por cento e trinta e quatro escolas, sendo que cento e onze escolas estão no meio rural e vinte e três estão situadas no meio urbano, com um total de 18.813 alunos matriculados, sendo 8.054 alunos na zona urbana e 10.759 alunos matriculados na zona rural.

O cenário educacional das escolas do Campo, historicamente tem demonstrado que na maioria das vezes, essas escolas são deixadas de lado pelo poder público, os investimentos no campo são poucos em relação às escolas urbanas.

Além disso, a distância de uma comunidade para outra é considerável e por não ter alunos suficientes para completar o número de turmas, por isso, em algumas escolas do campo, a organização é multisseriada, pelo fato de não possuírem números suficientes de alunos para fechar uma turma seriada. Segundo Hage (2008):

Em geral, essas escolas são alocadas em prédios escolares depauperados, sem ventilação, sem banheiros e local para armazenamento e confecção da merenda escolar, possuindo estrutura física sem as condições mínimas para funcionar uma escola. (HAGE, 2008, p. 1).

Assim, para coibir a permanência de tal precarização, os investimentos do Governo Federal representam crescimento e avanço para as comunidades contempladas com tais benefícios, inclusive para o Município de Bragança por meio do PAR nos últimos quatro anos. Nesse estudo, destacamos o financiamento a espaços escolares nas comunidades do Km 10 do Montenegro e na Vila dos Lucas, ambas contempladas com um projeto padrão de espaço educativo rural de duas salas de aula em parceria com SEMED Bragança-PA, conforme a Figura 1 a seguir: 
Figura 1 - Projeção de um projeto padrão de duas salas

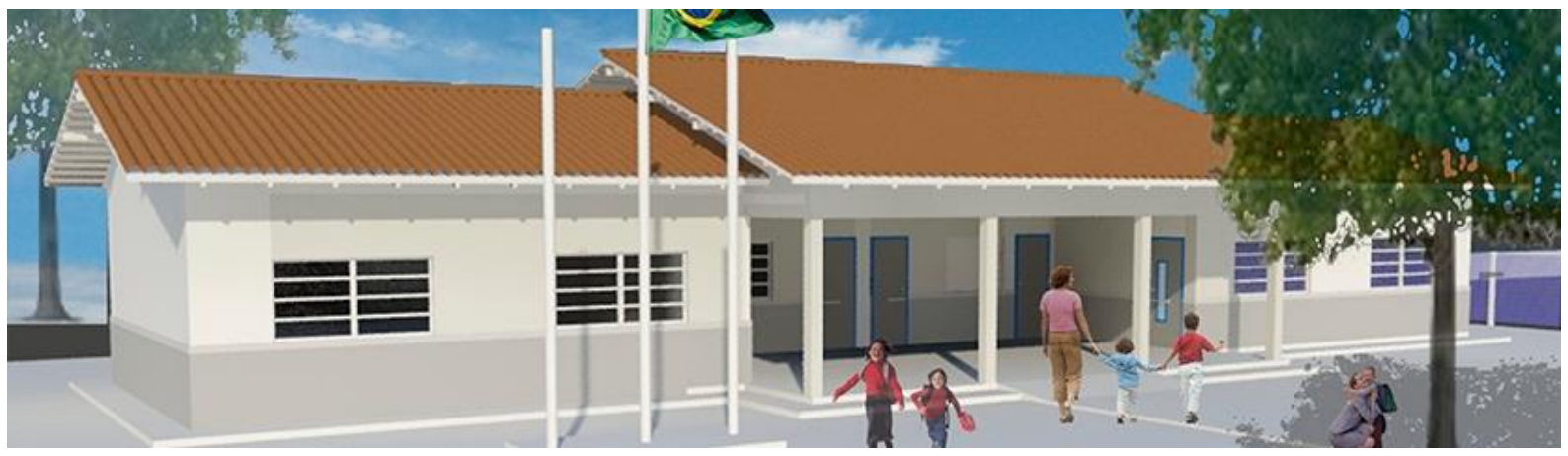

Fonte: Ministério da Educação.

Essa figura é uma projeção arquitetônica do projeto padrão que segue as exigências arquitetônicas do MEC, financiado a partir do PAR, esse projeto tem duas salas de aula, um hall de entrada, dois banheiros adaptados para acessibilidade, uma secretaria, uma cozinha, sendo que a SEMED atua como agente fiscalizadora do processo construtivo e não pode fazer alterações no projeto financiado.

É importante ressaltar que apesar de ser um projeto que não pode ser alterado, os investimentos, disponibilizados pelo PAR, para essas comunidades, são representativos se comparados às condições anteriores, em que os prédios estavam deteriorados, não estimulava o desenvolvimento da aprendizagem dos alunos.

Segundo dados do Departamento de Estatística da SEMED, a Escola Municipal de Ensino Fundamental Zacharias da Silveira Miranda atende 59 alunos distribuídos na Educação Infantil, Ensino Fundamental e ainda atua no Programa Mais Educação (turno vespertino). A estrutura física da escola é composta por três salas de aula, uma secretaria, uma cozinha e dois banheiros com adaptação para acessibilidade. O corpo funcional da escola é composto por três professores, sendo que um atua no Programa Mais Educação, dois auxiliares de serviços gerais e um vigia.

A seguir apresentamos a estrutura da escola anterior à reforma e sua reestruturação a partir do financiamento do PAR. A Figura 2 mostra a Escola antes da reforma, já a Figura 3 mostra a escola após a construção do novo prédio. 
Figura 2 - Escola Municipal de Ensino Fundamental Zacharias Miranda da Silveira

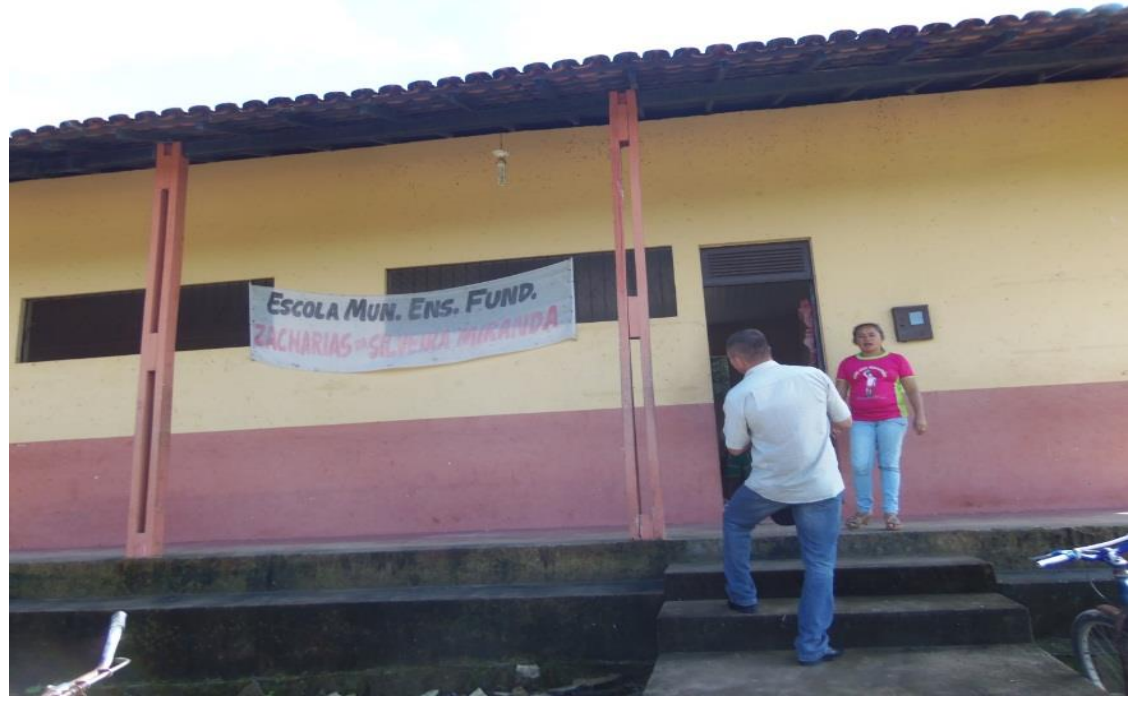

Fonte: Acervo da SEMED.

Com base nessa fotografia e visitas in loco, pontuamos alguns aspectos no antigo prédio que estavam fora dos padrões estipulados pelas leis educacionais, dentre eles, a acessibilidade. Como podemos observar a partir da fotografia, o prédio está situado em um terreno com um desnível muito elevado com relação à rua, pontuamos como um problema para alunos com deficiência física, tendo em vista que o prédio não dispunha de rampas de acesso. A escola anterior dispunha de uma sala de aula, um banheiro e uma cozinha.

Podemos destacar que anterior a construção, a escola apresentava problemas com relação a cobertura, conforme relatos de profissionais que atuam na escola, visto que, no período de inverno, as goteiras e o número de morcegos que se abrigavam no forro impediam, por vezes, a ministração das aulas.

Figura 3 - Escola Municipal de Ensino Fundamental Zacharias Miranda da Silveira

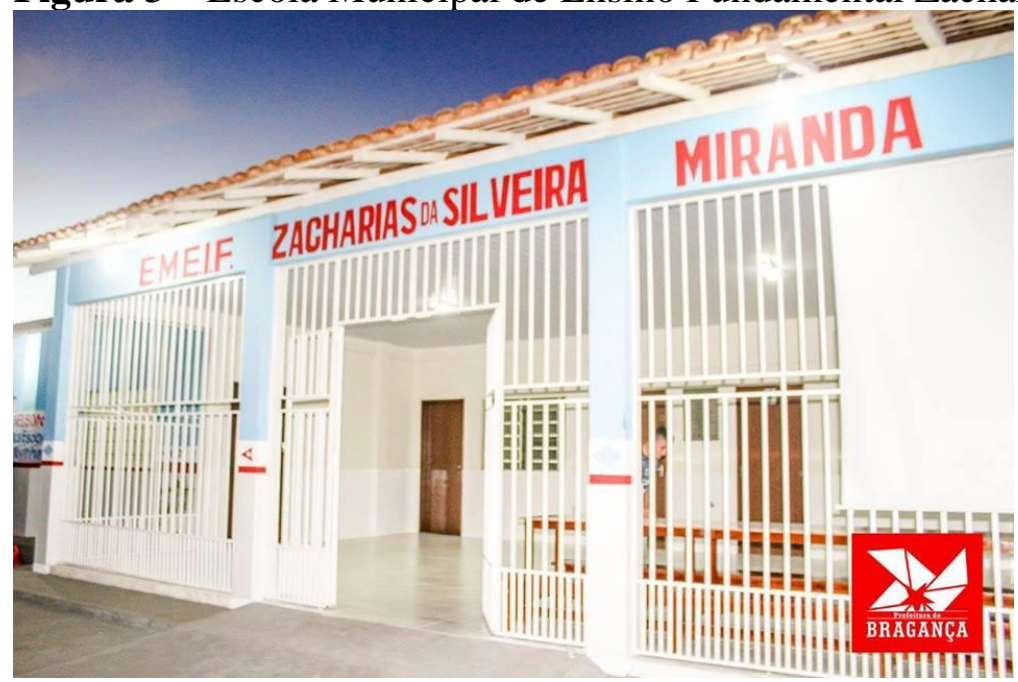

Fonte: Acervo da SEMED. 
A partir da construção do novo prédio, é possível enfatizar a melhoria para a inclusão de pessoa com deficiência na participação das atividades, pois, a escola, atualmente, dispõe de rampas de acesso para cadeirantes no interior do prédio e de mais duas salas de aula, uma cozinha, uma secretaria, dois banheiros com adaptação para deficientes e um hall de acesso e recreação.

A Escola Municipal de Ensino Fundamental Manoel Lucas atende cerca de 34 alunos distribuídos na Educação Infantil, Ensino Fundamental e Educação de Jovens e Adultos (EJA). A estrutura física da escola é composta por duas salas de aula, uma secretaria, uma cozinha e dois banheiros. O corpo funcional da escola é composto por dois professores, dois auxiliares de serviços gerais e um vigia.

A Figura 4 mostra o prédio escolar antes das ações do PAR e a Figura 5, mostrando o depois da reestruturação da Escola.

Figura 4 - Escola Municipal de Ensino Fundamental Manoel Lucas

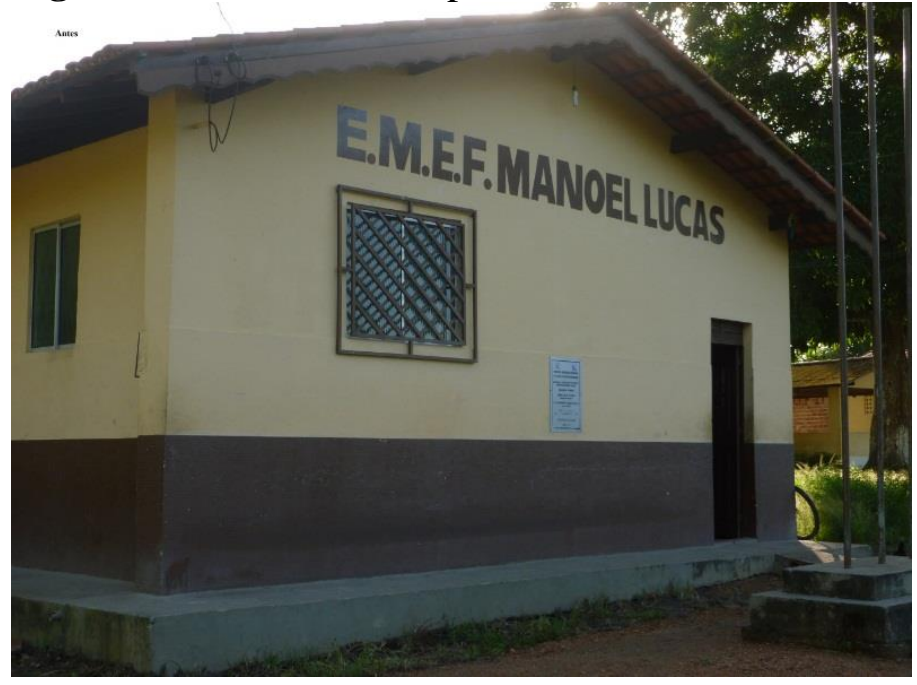

Fonte: Acervo fotográfico do autor.

Observando a Figura 4, é possível verificar que a escola anteriormente as ações do PAR tinha apenas uma sala de aula, não dispunha de rampas de acessibilidade, logo, não existia nem possibilidade para pessoas com deficiência como cadeirante adentrarem na escola, tendo em vista que as medidas da porta principal são inferiores ao estipulado pelas normas de acessibilidade. 
Figura 5 - Escola Municipal de Ensino Fundamental Manoel Lucas

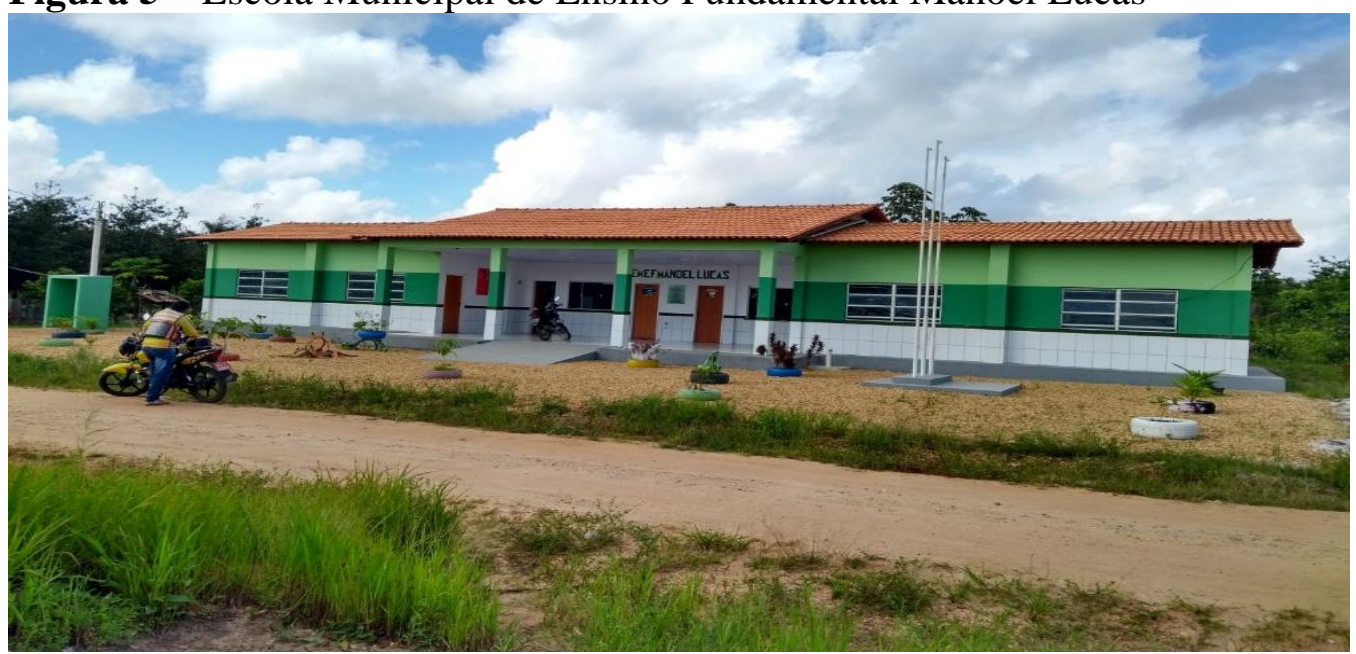

Fonte: Acervo fotográfico do autor.

A partir da visita na escola antes e após a construção e considerando essas imagens mostradas, ressaltamos a diferença estrutural do prédio. Esse aspecto que possibilita a comunidade escolar uma melhoria no processo de ensino-aprendizagem, uma vez que a escola que antes tinha apenas uma sala de aula, agora contém duas salas. Além de espaço de entrada que pode ser utilizado como espaço de convivência, colocamos ainda o fator acessibilidade que a partir da construção da nova escola, favoreceu o acesso dos alunos com deficiência.

\subsection{Discursos de professores sobre a infraestrutura da escola do campo e seus reflexos na qualidade do processo de ensino- aprendizagem em Bragança-PA}

Na maioria das vezes, a infraestrutura escolar, ofertada nas comunidades do campo, segundo Hage (2008), são desfavoráveis, não estimula os professores nem os alunos a permanecerem na escola, ou sentir orgulho de estudar em sua própria comunidade. Mediante a situação, observamos no Decreto 7.352/2010, no inciso $4^{\circ}$, a definição que a educação do campo concretizar-se-á mediante a oferta de uma série de condições, incluindo a garantia de infraestrutura escolar, entre outros aspectos importantes para o desenvolvimento da educação do campo.

A escola do campo deve ser entendida como espaço formativo dotado de efetiva disponibilidade de tempos para a sua utilização e acessibilidade, conforme assegura as Diretrizes Curriculares Nacionais Gerais para a Educação Básica (DCNGEB). A partir disso, entendemos que a infraestrutura nas instituições de ensino do campo é uma das condições fundamentais para o exercício pedagógico. Por isso, a Educação do Campo deverá oferecer sempre o indispensável apoio pedagógico aos alunos, incluindo condições com infraestrutura acessível (BRASIL, 2013). 
Nesse sentido, perguntamos aos professores como percebem atualmente a infraestrutura da escola do campo. Os discursos foram sintetizados da seguinte forma:

Percebe-se que vem avançando com o passar dos tempos, mais que ainda precisa se ajustar de acordo com as necessidades da própria comunidade onde está inserida. (Professor A, Entrevista semiestruturada, 2018).

Na escola [...] a infraestrutura é boa, com a construção do novo prédio ficou tudo melhor, salas com ar condicionado, banheiros adaptados etc. (Professor B, Questionário, 2018).

Em sua grande maioria encontra-se com prédios velhos, apresentando espaços físicos inadequados [...] comprometendo a qualidade do ensino aprendizagem. (Professor $C$, Questionário, 2018).

Na realidade, percebemos uma grande diferença não só na questão do investimento [...], mas na estrutura física das escolas do campo a partir do PAR. Contudo, a gente percebe uma grande dificuldade na questão da infraestrutura de algumas escolas do campo, mas de fato o PAR começou a desenvolver esse investimento nessas escolas do campo [...]. (Professor D, Entrevista semiestruturada, 2018).

Os sentidos dos discursos revelam que a infraestrutura da escola avança, mas precisa de ajustes, conforme a necessidade da comunidade. Percebemos também o reconhecimento da infraestrutura adequada a partir da construção da nova escola. Mas, a despeito de seus avanços ainda é possível perceber que a maioria das escolas do campo apresentam espaços físicos inadequados o que compromete a qualidade do processo de ensino. No entanto, é inegável os benefícios dos investimentos relacionados à infraestrutura da escola do campo, a partir do PAR. De modo geral, a maioria acredita na melhoria do espaço físico para a qualidade da educação.

As escolas do campo na realidade bragantina, conforme visita técnica realizada antes da reestruturação das escolas, em sua maioria, têm telhados comprometidos que durante o inverno são problemas, as salas de aula pouco confortáveis com iluminação, ventilação, sonoridade etc. precárias, sem falar nas paredes sujas, cadeiras quebradas, quadros pequenos e em muitos ainda utilizam-se giz o compromete a saúde docente e dos demais agentes da escola.

O PAR apresenta-se como uma estratégia técnica e financeira, um plano para se alcançar um objetivo, permitindo oferecer, aos entes federados, instrumentos para chegar a um diagnóstico educacional do município e, assim, seja possível fazer os planejamentos necessários, de acordo com as necessidades inerentes, contribuindo para melhoria da qualidade na educação.

A execução dessas políticas públicas deve estar associada ao princípio de gestão democrática, pois é um processo a ser construído, com a participação de todos os agentes que compõem o espaço escolar. Desse modo, “[...] a proposta é que o PAR seja construído de forma a promover a participação ativa dos gestores, educadores locais, das famílias e da comunidade, 
e assim resguardar a organicidade das ações" (FERREIRA; FONSECA, 2011, p. 85). A construção e o planejamento das ações são importantes nesse processo, pois valoriza os envolvidos e leva em consideração as necessidades e as especificidades da comunidade, possibilitando uma construção democrática. Vejamos os discursos mais expressivos:

[...] então com a nova estrutura do prédio, houve muita melhoria porque ganhamos mais duas salas climatizadas, cozinha com espaço maior para as crianças brincarem e fazer suas refeições [...]. (Professor A, Entrevista semiestruturada, 2018).

Acredito que sim. Porque com essa nova política, o município ganhou inúmeros prédios, principalmente no campo, onde a infraestrutura das escolas era de péssima qualidade. (Professor B, Questionário, 2018).

Com certeza, isso aí a gente percebe notoriamente, enquanto educador que após a implementação do PAR, as mudanças foram significativas no que diz respeito a infraestrutura das escolas do campo. (Professor D, Entrevista semiestruturada, 2018).

As mudanças na infraestrutura, segundo os entrevistados foram perceptíveis. O professor A associa a melhoria ao fato da ampliação de salas e ao conforto térmico que dispunham a partir da climatização, destacando o hall de entrada que possibilita maior conforto na hora do lanche das crianças; já o Professor B compara a melhoria dessas construções ao cenário anterior em que se tinha prédio sem condições de trabalho, enfatizando como de péssima qualidade; e por fim, o Professor D descreve as mudanças como notória a todos os envolvidos, ou seja, a construção de uma nova escola trouxe consigo melhorias na infraestrutura.

A partir da reestruturação das escolas é possível perceber mudanças na melhoria dos espaços, as salas são mis confortáveis, espaçosas, com cadeiras que proporcionam conforto, as janelas são maiores, proporcionando melhor luminosidade ao ambiente, entre outros. É importante também considerar que para esses docentes que estão diariamente nesse espaço do campo, vivenciando esses aspectos referentes à infraestrutura, essas construções significam muito com relação ao que se tinha antes.

As mudanças na infraestrutura dessas escolas são visíveis, por isso, questionamos os professores se a infraestrutura da escola atualmente consegue suprir as necessidades para o desenvolvimento do ensino e da aprendizagem dos alunos das escolas do campo. Os discursos revelam: 
Infelizmente ainda não [...]. Eles precisam de uma sala de informática, uma sala de leitura. Crianças com necessidades especiais precisam também ter um espaço só para eles, que venham se ajustar de acordo com as necessidades. O espaço de recreação também é importante, [...] a gente fica se questionando que seria ideal um espaço com uma pracinha, com um campo de futebol adequado para crianças [...]. (Professor A, Entrevista semiestruturada, 2018).

Acredito que sim. Porque com uma sala de aula mais adequada, os alunos conseguem ficar mais confortáveis, sem se incomodar com as péssimas qualidades de antes. (Professor B, Questionário. 2018).

Em sua grande maioria sim, atualmente encontra-se em melhores condições físicas, conseguindo suprir grande parte das necessidades que existiam. (Professor $C$, Questionário, 2018).

Por experiência própria em duas escolas do campo, onde uma foi construída a partir do $P A R$, a gente percebeu de fato o desenvolvimento dos alunos em relação a [...] infraestrutura [...] do novo modelo criado pelo MEC e aplicado pelo PAR. (Professor D, Entrevista semiestruturada, 2018).

É possível perceber a partir dos discursos que alguns docentes são bem contundentes em dizer que somente a infraestrutura atual ofertada pelo PAR não consegue suprir as necessidades para o desenvolvimento do ensino e da aprendizagem dos alunos, visto que o aprendizado não se resume apenas a uma sala de aula bem estruturada em termos técnicos.

Candau (2012), ao tratar sobre o ensino, aponta a multidimensionalidade do processo de ensino e de aprendizagem e corrobora que este deve estar relacionado às dimensões humanas, técnicas e políticas-sociais. Para ela, é nessas dimensões que os professores e suas diversas estruturas didáticas devem se situar em relação à educação. Portanto, a multidimensionalidade do ensino é fundamental para o desenvolvimento do ensinoaprendizagem, no entanto, os insumos escolares (infraestrutura de todo tipo) são muito importantes na definição dos resultados educacionais.

Para Sátyro, Ferreira e Soares (2007), a deficiência de infraestrutura nas escolas afeta diretamente a qualidade da educação. Prédios e instalações inadequadas, a inexistência de bibliotecas, espaços esportivos e laboratórios, a falta de acesso a livros didáticos, materiais de leitura, a relação inadequada ao tamanho da sala de aula e o número de alunos, são problemas que influenciam diretamente no desempenho dos alunos. Ressaltamos, ainda, as tecnologias, sala de informática, espaços de recreação, quadra de esportes etc., espaços fundamentais para o processo de ensino-aprendizagem, uma vez que este não se reduz somente a sala de aula, mas também as atividades extraclasses.

Podemos considerar que tanto a infraestrutura como recursos pedagógicos são princípios básicos que devem ser disponibilizados pelo poder público para que a educação 
aconteça em suas mais diversas modalidades de ensino, prezando pelo princípio da qualidade. A importância do PAR é perceptível nos discursos de professores, quando se referem às melhorias na infraestrutura, nas contribuições para o desenvolvimento do processo pedagógico. Nesse sentido, os docentes, como também todos que compõem a comunidade escolar, mencionam que o PAR contribui significativamente para a infraestrutura escolar, mas não atende algumas necessidades/ realidades das escolas do campo para a qualidade do processo de ensino aprendizagem.

A qualidade do ensino-aprendizagem envolve muitas práticas e técnicas pedagógicas, dentre muitos aspectos necessários a essa qualidade, destacamos as políticas públicas educacionais no tocante aos projetos que visem o financiamento da infraestrutura e recursos pedagógicos. Ferreira e Fonseca (2011, p. 51) afirmam que “[...] a qualidade da educação vista como um processo formado por um conjunto de ações que não se concentram apenas no ensino, mas em todo o processo educacional".

Para Dourado, Oliveira e Santos (2007), a qualidade social caracteriza-se por:

Conjunto de fatores intra e extraescolares que se referem as condições de vida dos alunos e de suas famílias, ao seu contexto social, cultural e econômico e à própria escola - professores, diretores, projeto político pedagógico, recursos, instalações, estrutura organizacional, ambiente escolar e relações intersubjetivas no cotidiano escolar. (DOURADO; OLIVEIRA; SANTOS, 2007, p. 940).

Dourado, Oliveira e Santos (2007) consideram os aspectos intra e extraescolares como sendo primordiais para que se alcance a qualidade da educação, considerando as questões sociais que permeiam a escola, quanto à multiplicidade que compõe cada grupo social. Neste estudo, nos atemos aos aspectos intraescolares, concernentes aos recursos e instalações, pois vemos como fator importante no processo de qualidade do ensino-aprendizagem, tendo em vista que, para obter bons resultados, é necessário oferecer infraestrutura e ferramentas que auxiliem o professor nesse processo.

Os professores descreveram a qualidade do ensino sobre as influências que a infraestrutura da escola trouxe para o processo de ensino-aprendizagem dos alunos. A esse respeito, os discursos revelam: 
[...] quando as crianças se depararam com esse espaço melhor, mais bonito, mais confortável, eles mesmo começaram a ver que precisavam avançar junto com a gente no aprendizado. (Professor A, Entrevista semiestruturada, 2018).

Espaços arejados, climatizados, espaços mais amplos, melhores condições para se desenvolver atividades em classe. (Professor C, Questionário, 2018).

Algo que é significativo hoje é autoestima dos alunos e também dos profissionais que atuam na escola, haja vista que, onde você chega que percebe um ambiente limpo, cuidado, com uma infraestrutura adequada, mobília, parte pedagógica, a gente logo percebe no semblante dos alunos, dos profissionais que de fato a infraestrutura influencia. A questão da assiduidade dos alunos melhorou, aquela questão de não querer faltar, de estar participando das atividades intra e extraclasse. (Professor D, Entrevista semiestruturada, 2018).

A partir dos discursos, percebemos que a infraestrutura atual da escola proporciona mais conforto e autoestima tanto para professores quanto para os alunos. O professor A descreve que o ambiente proporcionou a motivação para o ensino-aprendizagem. Da mesma maneira, o Professor D associa os novos ambientes com a melhora da assiduidade dos alunos, ou seja, os alunos atualmente sentem-se bem na escola, são mais participativos nas atividades escolares.

Notamos a que a infraestrutura escolar ofertada pelo PAR estimulou os alunos e profissionais da escola a exercerem suas funções com mais motivação, salas mais amplas e climatizadas e propícias à ventilação, proporcionam mais conforto e bem-estar, estimulando os educandos à assiduidade.

O processo de ensino e de aprendizagem requer recursos e espaços que propicie conforto para um maior aproveitamento escolar. Para Beltrame e Moura (2009, p. 2), “[...] é importante considerar que para a ocorrência da qualidade deste processo de ensino e aprendizagem é fundamental existir certa harmonia entre os dois componentes: a arquitetura e o pedagógico". Além disso, a garantia de insumos adequados é condição necessária - ainda que não suficiente - para a qualidade do ensino (CARREIRA; PINTO, 2007).

Os investimentos relacionados à infraestrutura são necessários, pois uma escola necessita de instalações e materiais de qualidade, uma vez que o processo de ensinoaprendizagem é muito complexo e requer mais do que estrutura. A esse respeito questionamos: Em sua opinião, quais os investimentos que precisam ser empregados na infraestrutura para o crescimento e avanços na qualidade da educação? Os enunciados discursivos mais expressivos revelam: 
Investimento na acessibilidade e formação para professores das escolas do campo voltado para o campo, porque geralmente nossas formações acontecem na cidade junto com todos. (Professor A, Entrevista semiestruturada, 2018).

Precisa-se melhorar o uso da internet, que já não está funcionando mais, [...] a sala de informática para que assim os alunos possam usufruir desses recursos [...]. (Professor B, Questionário, 2018).

[...] falta muito investimento na educação, não só em Bragança, eu acredito que quando os nossos governantes olharem a educação como algo primordial e a redenção dos problemas sociais no Brasil e de fato direcionarem recursos suficientes para investimento não só na infraestrutura, mas também na ampliação da formação docente, técnica, a educação vai avançar. (Professor D, Entrevista semiestruturada, 2018).

Os discursos mais expressivos revelam que somente a infraestrutura atual, ofertada pelo PAR, não consegue suprir todas as necessidades para o desenvolvimento do ensinoaprendizagem dos alunos, outros investimentos precisam ser feitos para complementar esse processo, são eles: investimentos em acessibilidade, sala de informática, acesso à internet como descreve o professor B e a formação docente, voltada para a educação do campo.

Considerando a opinião dos professores, mesmo os novos prédios escolares apresentando rampas, banheiros adaptados para acessibilidade, ainda assim, podemos identificar no discurso do professor $\mathrm{A}$, a necessidade de mais investimentos na área de acessibilidade. Nesse sentido, entendemos que a acessibilidade não se resume a rampas de acesso e a banheiros adaptados, visto que, a escola como um espaço formador deve dispor de infraestrutura que atenda todos as pessoas, sem exceções, inclusive ser um espaço que dê condições para a participação de pessoas com deficiências, afinal, a educação especial está assegurada pela Lei $\mathrm{n}^{\mathrm{o}} 7.853$ que dispõe sobre a obrigatoriedade da educação especial em estabelecimentos de ensino público e privado.

De modo geral, os discursos de professores sobre a influência da infraestrutura, ofertada pelo PAR para o desenvolvimento do ensino e da aprendizagem, resumem que esta é boa e significativa, representa avanços e contribui para o conforto dos profissionais e alunos que compõem essas escolas contempladas por uma política educacional que representa investimentos na infraestrutura de algumas escolas do campo no município de Bragança-PA.

\section{Considerações finais}

O presente estudo possibilitou analisar a influência da infraestrutura das escolas do campo ofertada pelo PAR e seus reflexos no processo de ensino e de aprendizagem. Diante de todos os argumentos apresentados no decorrer deste estudo, constatamos que o PAR surgiu como ferramenta muito importante de articulações, em diferentes dimensões, tal como de 
infraestrutura como também gestão educacional; formação de professores e dos profissionais de serviço e apoio escolar; práticas pedagógicas de avaliação e recursos pedagógicos, considerados importantes para a qualidade da educação.

Notamos que apesar do PAR ter abrangência na Modalidade da Educação do Campo, ainda não consegue atender as demandas e suprir as deficiências, presentes na escola do campo em termos de infraestrutura, mesmo quando os professores consideram a infraestrutura escolar boa, ainda, assim, eles destacam a necessidade de outros espaços que também contribuem para o processo de ensino e de aprendizagem.

Apesar das contribuições do PAR com relação à infraestrutura apresentar mudanças que colaboram com o processo de ensino e de aprendizagem, de acordo com os entrevistados, as escolas precisam de outros espaços e investimentos, tais como: área de recreação e esporte, laboratório de informática, biblioteca, sala de leitura, espaços adaptados para pessoas com deficiência e a formação de docentes para a educação do campo são imprescindíveis para o desenvolvimento do ensino-aprendizagem.

Concluímos que os investimentos do PAR para o Município de Bragança-PA apresentam-se como fator de transformação na infraestrutura de algumas escolas do campo, no entanto, essa política precisa se adequar as especificidades das comunidades do campo, considerando as opiniões e as especulações dos profissionais que atuam diretamente nesses espaços, sendo que que a infraestrutura é um fator importante para a qualidade do ensino e da aprendizagem dos alunos do campo.

\section{Referências}

BELTRAME, M. B., MOURA, G. R. S. Edificações escolares: infraestrutura necessária ao processo de Ensino e aprendizagem escolar. Revista eletrônica Travessias, Cascavel, v. 3, n. 2, p. 1-15, 2009. Disponível em:

http://e-revista.unioeste.br/index.php/travessias/article/view/3378/0. Acesso em: 8 nov. 2017.

BRASIL. [Constituição (1988)]. Constituição da República Federativa do Brasil de 1988. Brasília, DF: Presidência da República. Disponível em: http://www.planalto.gov.br/ccivil_03/constituicao/constituicao.htm. Acesso em: 14 fev. 2018.

BRASIL. Lei $n^{o} 13.005$, de 25 de junho de 2014. Aprova o Plano Nacional de Educação (PNE) e dá outras providências. Brasília: Câmara dos Deputados, 2014.

BRASIL. Diretrizes operacionais para a educação básica das escolas do campo. Brasília: MEC, 2013. 
BRASIL. Lei $n^{\circ}$ 9.394, de 20 de dezembro de 1996. Estabelece as diretrizes e bases da educação nacional. Brasília: Casa Civil da Presidência da República Federativa do Brasil, 1996.

BRASIL. Decreto $n^{\circ}$ 6.094, de 24 de abril de 2007. Dispõe sobre a implementação do Plano de Metas Compromisso Todos pela Educação, pela União Federal, em regime de colaboração com Municípios, Distrito Federal e Estados, e a participação das famílias e da comunidade, mediante programas e ações de assistência técnica e financeira, visando a mobilização social pela melhoria da qualidade da educação básica. Brasília, DF, Presidência da República. Disponível em: http://www.planalto.gov.br/ccivil_03/_ato2007-2010/2007/decreto/d6094.htm Acesso em: 15 set. 2018.

BRASIL. Decreto $n^{o} 7.352$, de 4 de novembro de 2010. Dispõe sobre a política de educação do campo e o Programa Nacional de Educação na Reforma Agrária - PRONERA. Brasília, DF, Presidência da República. Disponível em:

http://www.planalto.gov.br/ccivil_03/_ato2007-2010/2010/decreto/d7352.htm.

Acesso em: 15 set. 2018.

BRASIL. Lei $n^{\circ} 7.853$, de 24 de outubro de 1989. Dispõe sobre o apoio às pessoas portadoras de deficiência, sua integração social, sobre a Coordenadoria Nacional para Integração da Pessoa Portadora de Deficiência - Corde, institui a tutela jurisdicional de interesses coletivos ou difusos dessas pessoas, disciplina a atuação do Ministério Público, define crimes, e dá outras providências. Brasília, DF, Presidência da República. Disponível em: http://www.planalto.gov.br/ccivil_03/leis/L7853.htm. Acesso em: 15 set. 2018.

BRASIL. Fundo Nacional de Desenvolvimento da Educação (FNDE). Disponível em: http://www.fnde.gov.br/programas/par?view=default. Acesso em: 16 dez. 2017.

BRASIL. Manual Técnico-operacional do Módulo de Monitoramento do Plano de Ações Articuladas (PAR). Brasília: MEC, 2009.

CANDAU, V. M. A didática em questão. Petrópolis: Vozes, 2012.

CARREIRA, D.; PINTO, J. de R. Custo aluno qualidade inicial: rumo a uma educação pública de qualidade no Brasil. São Paulo: Global, 2007.

DOURADO, L. F.; OLIVEIRA, J. F.; SANTOS, C.A. A qualidade da educação: conceitos $e$ definições. Brasília: Instituto Nacional de Estudos e Pesquisas Educacionais Anísio Teixeira, 2007.

FERREIRA, E. B; FONSECA, M. O planejamento das políticas educativas no Brasil e seus desafios atuais. Revista Perspectiva, Florianópolis, v. 29, n. 1, p. 69- 96, jan./jun. 2011.

HAGE, S. A. M. A multissérie em pauta: para transgredir o paradigma seriado nas escolas do campo, 2008. Disponível em:

https://www.faced.ufba.br/sites/faced.ufba.br/files/multisserie_pauta_salomao_hage.pdf. Acesso em: 30 mar. 2018.

LOBO, G. M. O.; BARBALHO, M. G. C. O. Plano de ações articuladas e a base legal para sua formulação. In: LOBO, G. M. O.; BARBALHO, M. G. C. O. Dimensões do PAR: contextos e estratégias de implementação. Campinas: Mercado de Letras, 2017. p.75-98. 
MARCONI, M. de A.; LAKATOS, E. M. Técnicas de pesquisa: planejamento e execução de pesquisas, elaboração, análise e interpretação de dados. 5. ed. São Paulo. Atlas, 2002.

MINAYO, M. C. S. O desafio do conhecimento. 9. ed. São Paulo: Hucitec, 2006.

ORLANDI, P. E. Análise de discurso: princípios e procedimentos. 3. ed. Campinas: Unicamp, 2001.

SÁTYRO, N; FERREIRA, E. B; SOARES, S. A infraestrutura das escolas brasileiras de ensino fundamental: um estudo com base nos censos escolares de 1997 a 2005. Textos para Discussão, n. 1267. Brasília: IPEA, 2007.

SANTOS, R. A. dos. In: visibilidade negra: representação social de professores acerca das relações raciais no currículo escolar do Ensino Fundamental em Ananindeua (PA). 2009. Dissertação (Mestrado em Educação) - Universidade Federal do Pará, Belém, 2009. 